\title{
Влияния различных фракторов на сорбционные взаимодействия электропроводящего полимера с вирусами гриппа
}

\author{
Иванова В.Т. ${ }^{1}$, Гарина Е.О. ${ }^{1}$, Сапурина И.Ю. ${ }^{2}$, Стейскал Я. $^{3}$, \\ Грибкова О.Л. ${ }^{4}$, Кириллова Е.С. ${ }^{1}$, Иванов В.Ф. ${ }^{4}$, Бурцева Е.И. ${ }^{1}$ \\ ${ }^{l}$ ФГБУ «ФНИЦЭМ им. Н.Ф. Гамалеи» Минздрава России, Москва \\ ${ }^{2}$ Институт высокомолекулярных соединений РАН, Санкт-Петербург \\ ${ }^{3}$ Институт макромолекулярной химии Академии наук Чешской Республики,. Прага \\ ${ }^{4}$ Институт физической химии и электрохимии им. А. Н. Фрумкина РАН, Москва
}

Поступила в редакцию 19.05.2017 г.

Для сорбции вирусов гриппа из водной среды применен электропроводящий полимер полипиррол с сопряженной структурой цепей. Исследована эффективность связывания вируса полимером для чего, использованы различные факторы, разрушающие сорбционные взаимодействия: воздействие растворителя, повышенная температура, ультразвук. Изучена возможность десорбции вируса под действием перечисленных факторов. Определена инфекционная активность вирусов в обработанных сорбентом водных средах, в комплексах с полимером, у десорбированных вирусов.

Ключевые слова: адсорбция, полипиррол, полианилин, вирусы гриппа, температурная и ультразвуковая обработка.

\section{Influences of various factors on the sorption interactions of conducting polymer with respect to influenza viruses}

\author{
Ivanova V.T. ${ }^{1}$, Garina E.O. ${ }^{1}$, Sapurina I.Yu. ${ }^{2}$, Stejskal J. ${ }^{3}$, Gribkova O.L. ${ }^{4}$, \\ Kirillova E.S. ${ }^{1}$, Ivanov V.F. ${ }^{4}$, Burtseva E.I. ${ }^{1}$ \\ ${ }^{I}$ D.I. Ivanovsky Institute of Virology FSBI “N.F. Gamaleya FRCEM" MoPH of the RF, Moscow \\ ${ }^{2}$ Institute of Macromolecular Compounds, Russian Academy of Sciences, Saint-Petersburg \\ ${ }^{3}$ Institute of Macromolecular Chemistry, Academy of Sciences of the Czech Republic, \\ Prague, Czech Republic \\ ${ }^{4}$ A.N. Frumkin Institute of Physical Chemistry and Electrochemistry RAS, Moscow
}

Electrically conductive polymer, polypyrrole with conjugated chain structure, being an insoluble and non-toxic compound and possessing a developed surface and a porous structure, is capable to interact with a wide range of organic and inorganic compounds, including heavy metal ions, organic toxins and micro pathogens: bacteria and viruses. In order to use polypyrrole for deep water purification, the sorption interactions of the polymer with influenza viruses have been studied. The influences of various factors that destroy sorption interactions (solvent exposure, elevated temperature and ultrasound) on interaction of the polymer with the virus have been discussed. The possibility of desorption of the virus under the influence of the above factors has been studied. The infectious activity of virus in the aqueous media treated with the sorbent, as well as of the virus bounding to the polymer and the virus desorbed from polymer has been determined.

It was established that polypyrrole adsorbed the strains of viruses A (H3N2) from the aquatic environment by reducing their concentration from 32 to 256 times. Wherein, the polymer does not release the virus when dispersed in a fresh portion of the solvent. Regardless of the temperature and ultrasonic treatment, there are no infectious neither the aqueous phase nor the polypyrrole with a bound virus. However, lowfrequency ultrasound of low power can desorb the virus from the polymer, which is accompanied by the de- 
struction of the virus (the destruction of its outer shell). The heat treatment of polypyrrole itself showed that when it warms up to $100^{\circ} \mathrm{C}$, the sorption activity of polymer does not decrease.

The study showed that polypyrrole firmly holds the adsorbed virus, suppressing its infectivity. However, the desorption of the "dead" virus by ultrasound is possible, which opens up prospects for the regeneration of the sorbent and its repeated use. The work is relevant for the practical use of the polymer sorbent, the tasks of its regeneration and reusable use, as well as for solving auxiliary medical problems - the concentration of viruses from the solutions for analysis.

Keywords: sorption, polypyrrole, influenza viruses, temperature and ultrasound treatment.

\section{Введение}

Серьезной проблемой современности является очистка воды. Воду необходимо очищать не только от бытовых и промышленных отходов, но и от микропатогенов: бактерий и вирусов, распространяющихся водным путем. Сорбция как метод очистки воды является одним из самых эффективных и высокотехнологичных. На практике используют различные сорбенты, которые разделяют на минеральные и углеродные. К первым относятся силикагели, альмогели, цеолиты, ко вторым - активные угли, торф и другие материалы, получаемые при переработке органики [1]. Наиболее универсальными сорбентами, используемыми для глубокой очистки воды, являются активированные угли. Они сорбируют различные виды органических и неорганических загрязнений, а также биологические примеси. Однако сорбционная емкость углей недостаточна. Она основана только на слабых Ван-дер-Ваальсовых силах связывания. Отсутствие хемосорбции не позволяет эффективно связывать ионы тяжелых металлов и биологические объекты. Поэтому угли не удовлетворяют всему комплексу требований, предъявляемых к материалам подобного типа. Специфические сорбционные методы выделения биологических объектов, таких как аминокислоты, белки, нуклеиновые кислоты $[2,3,4]$ известны, но они достаточно специфичны и дороги. Необходима разработка новых типов сорбентов глубокой очистки воды, отличающихся эффективным взаимодействием с широким спектром трудно извлекаемых загрязнений, таких как неорганические канцерогены - ионы тяжелых металлов; органические токсины, являющиеся отходами производства красителей и лекарственных препаратов, а также возбудителей инфекционных заболеваний - микропатогенов.

Новым направлением является исследование в качестве сорбентов для очистки воды полимеров с системой полисопряжения, так называемых, электропроводящих полимеров [5, 6]. Установлено, что представители данного класса полимеров: полианилин (PANI) и полипиррол (РPy) (рис. 1), будучи нерастворимыми и нетоксичными и обладая развитой поверхностью и пористой структурой, способны сорбировать широкий круг органических и неорганических соединений, включая приведенные выше канцерогены и токсины $[7,8,9]$. Показана также возможность использования полимеров для связывания микропатогенов. В работе [10] сообщается о выделении кишечных вирусов с использованием магнитных микрочастиц, покрытых полимером диоксида кремния с аминопропильными группами. В серии недавних работ показано, что PANI и PPy, а также композиционные материалы на их основе, способны эффективно связывать ряд широко распространенных патогенных и условно патогенных бактерий [11] и сорбировать вирусы $[11,12,13]$. Изучена сорбция полимерами различных штаммов вирусов гриппа типа А и В, циркулирующих последние 15 лет в России и за рубежом [14], а также вирусов полиомиелита [13, 15]. Причем эффективность сорбции вирусов полимерами выше, чем у используемых в настоящее время углеродных сорбентов [12]. 
(a)<smiles>CC(C)(C)c1ccc(-c2ccc(C(C)(C)C)[nH]2)[nH]1</smiles>

(b)<smiles>CC(C)(C)Nc1ccc(Nc2ccc(C(C)(C)C)cc2)cc1</smiles>

Рис. 1. Химическая структура полипиррола (а) и полианилина (б).

В данной публикации приведены результаты исследования сорбционных взаимодействий РРу с вирусами гриппа. Изучается: 1 - прочность связывания полимера с вирусом, и факторы, влияющие на сорбционное взаимодействие; 2 - возможность десорбции вируса с полимера; 3 - опасность комплекса «полимер+вирус» в плане инфекционного заражения. Эти исследования актуальны для практического использования полимерных сорбентов, задач их регенерации и многоразового использования, а также для решения вспомогательных медицинских проблем - концентрирования вирусов из элюатов с целью последующего анализа.

\section{Эксперимент}

В работе были использованы:

Вирусы. Эпидемические штаммы вирусов гриппа А/Виктория/361/11, А/Швейцария/9715293/13 (H3N2), циркулирующие в период 2011-2015 гг. в России и мире.

Сорбенты. Электропроводящие полимеры: PANI в основной непроводящей форме (синтезирован согласно [16]), РРу в солевой электропроводящей форме, а также РРу, модифицированный частицами серебра PPy-Ag [17].

Сорбционные взаимодействия исследованы на комплексах «полимерный сорбент+вирус», которые получали методом, изложенным в работе [18] Сорбент диспергировали в водной среде. Сорбент диспергировали в водной среде - физиологическом растворе (ФР), содержащей вирус, затем осадок отделяли на низкоскоростной центрифуге (Combi-Spin), в условиях, когда вирус не осаждается. Водную фазу, содержащую несорбированный вирус («надосадок»), и выделенный осадок, представляющий собой комплекс «сорбент+вирус», исследовали на наличие вируса и инфекционную активность.

Процесс десорбции вирусов с сорбента включал:

1. Разведение комплексов «сорбент+вирус» (4 мг) раствором (ФР) (200 мкл) с последующим перемешиванием на орбитальном шейкере в течение от 15 до 60 мин при $22^{\circ} \mathrm{C}$ и $4^{\circ} \mathrm{C}$.

2. Прогрев сорбентов и комплексов «вирус+сорбент» в термостате «СНВС4.5.4.5.4/3И-1» при температурах 50, 100 и $150^{\circ} \mathrm{C}$.

3. Обработку ультразвуком (У3) (рабочая частота 40 кГц) в водяной бане «Bransonic 12» в течение 15 и 30 мин.

После десорбции следовало осаждение комплекса «сорбент+вирус» центрифугированием 5 минут при 3000 об/мин и анализ «надосадка» и комплекса.

Концентрацию вируса гриппа в водной среде до сорбции, после сорбции и после десорбции определяли по реакции гемагглютинации (РГА) при 0.75\% содержании эритроцитов крови человека. Результат представлен в виде ГА-титров. Реакция основана на эффекте агрегирования (слипания) эритроцитов под действием наружной оболочки вируса. 
Инфекционный титр определяли по цитопатическому эффекту вирус содержащих жидкостей и суспензий комплексов «сорбент+вирус» на монослой культуры клеток MDCK. Результат приведен в виде инфекционных титров, представляющих собой максимальное разведение вируссодержащего раствора, при котором еще происходит гибель клеток MDCK. Метод показывает жизнеспособность вируса и возможность вызвать инфекционный процесс в чувствительной системе, например, в клетках MDCK.

Приведенные в работе данные для каждого значения инфекционных титров и ГА-титров представляют собой статистически обработанный результат от трех до пяти независимых экспериментов.

\section{Обсуждение результатов}

Влияние растворителя - эффект разведения. Слабые сорбционные взаимодействия являются обратимыми. При разведении или замене растворителя свежей порцией равновесие сорбции-десорбции смещается, что приводит к выделению сорбированного агента в жидкую фазу. Как результат диффузии в порах сорбента, десорбция происходит во времени, однако времена процессов сорбции и десорбции обычно сопоставимы.

Предварительные исследования показали, что процессы сорбции в системе полимерный сорбент - вирус протекают достаточно быстро и завершаются в течение 15 мин [18]. Комплексы «сорбент+вирус» были получены при введении сорбентов РРу и PPy-Ag в раствор вируса гриппа А/Виктория/361/11 (H3N2), где сорбенты экспонировались на протяжении 1 часа при $22^{\circ} \mathrm{C}$. По завершению сорбции комплексы «сорбент+вирус» были выделены и переведены в свежую порцию физиологического раствора, где серия сорбентов находилась на протяжении разного времени: от 15 мин, до 24 часов и при разных температурах: либо $22^{\circ} \mathrm{C}$, либо $4^{\circ} \mathrm{C}$. Результаты исследований «надосадка» титрованием методом РГА после удаления комплексов «сорбент+вирус» из физиологического раствора (рис. 2) показывают, что независимо от времени экспонирования, вирус в них отсутствует. Таким образом, вирус, связанный полимерным сорбентом, в водную фазу не выделяется даже в случае 24-часового эскпонирования. Не оказывала влияние на результат и температура эскпонирования. Отсутствие вирусов в элюатах нельзя связать с незавершенностью процессов десорбции, т.к. времена экспонирования комплексов в свежем растворителе намного превышают времена сорбции. Полученные результаты позволяют сделать предварительное заключение о прочном связывании вируса полимерным сорбентом.

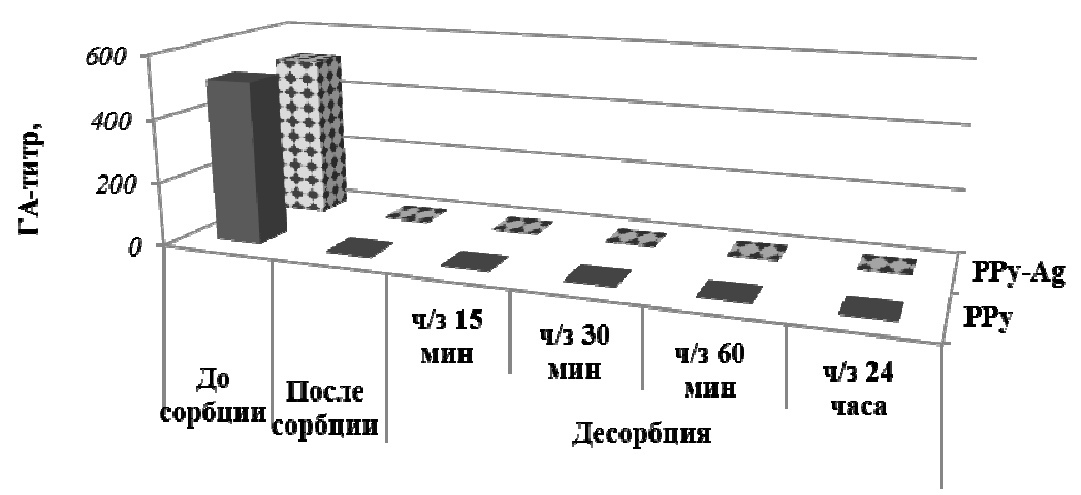

Рис. 2. Сорбция и десорбция концентрированного вируса гриппа $\mathrm{A} /$ Виктория/361/11 (H3N2) с РРу и РРy-Ag при $22^{\circ} \mathrm{C}$. 
Влияние температуры. Влияние температурной обработки рассматривалось в двух аспектах: во-первых, с точки зрения влияния на сорбционную активность самих полимерных сорбентов, во-вторых, с позиции воздействия температуры на десорбцию и дезактивацию вируса.

Влияние температурной обработки на сорбционную активность исследовалось с использованием двух полимеров: PРу и PANI, что позволяло сравнить характеристики двух полимерных сорбентов, эффективно связывающих вирусы [14]. Образцы PРу и PANI 30 минут прогревали в термостате при температурах 50, 100, $150^{\circ} \mathrm{C}$, а затем проводили стандартную процедуру сорбции вируса и определения инфекционных и ГА-титров в «надосадке» (таблица 1). Судя по ГА-титрам, сорбционная активность РРу, термообработанного при 50 и $100^{\circ} \mathrm{C}$, также высока, как у контрольных непрогретых образцов, и только при $150^{\circ} \mathrm{C}$ начинает снижаться. При этом независимо от температуры, инфекционная активность «надосадка» и комплекса «сорбент+вирус» не обнаруживается. В тоже время сорбционная активность PANI ниже, чем у РРу и уменьшается с ростом температуры до $100^{\circ} \mathrm{C}$, но при $150^{\circ} \mathrm{C}$ вновь растет и достигает уровня непрогретого образца. Инфекционные титры комплексов «РANI+вирус» и соответствующих «надосадков» изменяются в соответствии с ГАтитрами и демонстрируют наличие инфекции.

Таблица 1. Влияние термообработки PPy и PANI на сорбцию вируса гриппа А/Швейцария/9715293/13 (H3N2).

\begin{tabular}{|c|c|c|c|c|c|c|}
\hline \multirow[b]{2}{*}{ № } & \multirow[b]{2}{*}{ Сорбент } & \multirow{2}{*}{$\begin{array}{c}\text { Температу- } \\
\text { ра обработ- } \\
\text { ки сорбен- } \\
\text { тов, }{ }^{\circ} \mathrm{C}\end{array}$} & \multicolumn{2}{|c|}{ ГА-титр вируса в, ГАЕ } & \multicolumn{2}{|c|}{$\begin{array}{c}\text { Инфекционный титр по- } \\
\text { сле сорбции, } \lg \text { ТИД } \\
\end{array}$} \\
\hline & & & $\begin{array}{c}\text { p-pe до } \\
\text { сорбции }\end{array}$ & $\begin{array}{c}\text { надосадке } \\
\text { после сорб- } \\
\text { ции }\end{array}$ & надосадка & $\begin{array}{c}\text { комплекса } \\
\ll \mathrm{C}+\mathrm{B} » *\end{array}$ \\
\hline 1 & $\begin{array}{c}\text { РРу (кон- } \\
\text { троль) }\end{array}$ & $22-$ & \multirow{4}{*}{512} & 2 & 0 & 0 \\
\hline 2 & PPy-50 & 50 & & 2 & 0 & 0 \\
\hline 3 & PPy-100 & 100 & & 2 & 0 & 0 \\
\hline 4 & PPy-150 & 150 & & 8 & 0 & 0 \\
\hline 5 & $\begin{array}{l}\text { PANI (кон- } \\
\text { троль) }\end{array}$ & 22 & \multirow{3}{*}{512} & 8 & 2.5 & 1.5 \\
\hline 6 & PANI-50 & 50 & & 16 & 4.5 & 3.0 \\
\hline 7 & PANI-100 & 100 & & 32 & 5.0 & 3.0 \\
\hline
\end{tabular}

Снижение сорбционной активности РРу при прогреве при $150^{\circ} \mathrm{C}$ можно объяснить удалением из полимерной матрицы связанной воды. Как результат, гидрофобизация полимера ухудшает взаимодействия на интерфейсе с водной фазой и снижает сорбцию. Поведение PANI при прогреве более сложно. В принципе, используемая в работе основная форма PANI стабильна вплоть до $400^{\circ} \mathrm{C}$ и не подвержена химической деструкции. Тем не менее, при прогреве могут протекать структурные изменения в надмолекулярных агрегатах нерастворимого полимера [19], изменяющие пористость и проницаемость сорбента, что может менять его сорбционную активность.

Влияние температурной обработки на десорбцию вируса из комплекса «сорбент+вирус» исследовали на примере более стабильного и эффективного РРу (таблица 2). Комплексы «сорбент+вирус», полученные по стандартной методике при взаимодействии РРу и РPy-Ag с вирусом А/Швейцария/9715293/13 (H3N2), выделяли и обрабатывали в течение 30 минут при температурах 22,56 или $100^{\circ} \mathrm{C}$. После термообработки проводилось определение инфекционной активности как в «надо- 
садке», так и соответствующих комплексов «сорбент+вирус» на культуре клеток MDCK.

Таблица 2. Влияние температуры на инфекционный титр «надосадка» и комплекса «вирус-сорбент».

\begin{tabular}{|c|c|c|c|c|c|c|}
\hline \multirow[b]{2}{*}{ № } & \multirow[b]{2}{*}{ Сорбент } & \multicolumn{2}{|c|}{ ГА-титр вируса, ГАЕ } & \multirow{2}{*}{$\begin{array}{c}\text { Термообработка } \\
\text { комплекса «сор- } \\
\text { бент+вирус» }(30 \\
\text { мин }),{ }^{\circ} \mathrm{C}\end{array}$} & \multicolumn{2}{|c|}{$\begin{array}{c}\text { Инфекционный титр после } \\
\text { сорбции, } \lg \text { ТЦИД } \\
\end{array}$} \\
\hline & & $\begin{array}{l}\text { в р-ре до } \\
\text { сорбции }\end{array}$ & $\begin{array}{c}\text { в надосадке } \\
\text { после сорб- } \\
\text { ции }\end{array}$ & & надосадка* & $\begin{array}{l}\text { комплекса } \\
\text { «+ВГ»** }\end{array}$ \\
\hline 1 & \multirow{3}{*}{ PPy } & \multirow{3}{*}{512} & 16 & 25 & 0 & 0 \\
\hline 2 & & & 16 & 56 & 0 & 0 \\
\hline 3 & & & 16 & 100 & 0 & 0 \\
\hline 4 & \multirow{3}{*}{ Ag-PPy } & \multirow{3}{*}{512} & 2 & 25 & 0 & 0 \\
\hline 5 & & & 2 & 56 & 0 & 0 \\
\hline 6 & & & 2 & 100 & 0 & 0 \\
\hline
\end{tabular}

Примечание: Использовали конц. вирус гриппа А/Швейцария/9715293/13 (H3N2); Т(ГА)=512 ГАЕ. Инфекционный титр вируса $\pm 4.75 \lg$ ТИД 50 . *- надосадок НЕ ПОДВЕРГАЛИ воздействию Т. ** комплекс «С+ВГ» - комплекс сорбента с вирусом гриппа после сорбции и температурной обработки.

Анализ данных, приведенных в таблице 2, показывает, что для всех образцов инфекционная активность отсутствует, она не обнаруживается ни в «надосадке», ни в самом комплексе вне зависимости от термообработки. Судя по ГА-титрам, РРу несколько хуже выводит вирусы из раствора, чем РPу-Ag. Однако РРу, также, как и высокоактивный $\mathrm{PPy}-\mathrm{Ag}$, практически полностью подавляет инфекцию. Вирус дезактивируется не только в составе комплекса, но не проявляется также в водной фазе. Результаты показывают, что содержащий вирус ФР, прошедший сорбционную обработку полипирролом, дезинфицирован, и не требует тепловой обработки для обеззараживания. Инфекционно не активен и сам полимерный сорбент со связанным вирусом. Это означает, что после эксплуатации комплексы «РРу+вирус» не опасны и не требуют специальной утилизации.

Влияние ультразвуковой обработки. Известно, что УЗ может оказывать сильное влияние на микроорганизмы, и в том числе на вирусы. Однако это влияние сложно и неоднозначно, оно зависит как от частоты и мощности УЗ, так и от типа вируса, его концентрации в жидкой фазе, продолжительности и условий обработки [20]. В данной работе использован низкочастотный УЗ малой мощности. Выделенный по завершении сорбции комплекс «сорбент+вирус» в свежей порции ФР подвергали ультразвуковой обработке в течение 5,10,15 минут. Затем «надосадок» вновь отделяли от осадка и анализировали на наличие вируса и его инфекционную активность (таблица 3). Судя по ГА-титрам концентрация вируса в жидкой фазе нарастает с увеличением продолжительности УЗ обработки от 5 до 15 мин. Однако увеличение продолжительности до 30 мин приводит к снижению концентрации вируса. При этом во всех случаях инфекционная активность вирусов, как в комплексе «сорбент+вирус», так и в «надосадке», культурой клеток MDCK не регистрировалась. Результаты говорят о десорбции вируса с полимера под действием УЗ, однако десорбируется нежизнеспособный инфекционно неактивный вирус. По-видимому, десорбция сопровождается разрушением вирусной оболочки, что подтверждается следующим. ГА-активность вируса обеспечивается его оболочкой. При малых времена УЗ воздействия ГА-активность проявляется, что может свидетельствовать об элюции с сорбента полуразрушенного вируса с частично сохраненной наружной гемагглю- 
тинирующей оболочкой. Но при больших временах ГА активность исчезает, что вызвано полным разрушением оболочек.

Таблица 3. Влияние УЗ на десорбцию концентрированного вируса гриппа А/Швейцария/9715293/13 (Н3N2) из комплекса «сорбент+вирус».

\begin{tabular}{|c|c|c|c|c|c|c|c|}
\hline \multirow{4}{*}{ № } & \multirow{4}{*}{ Сорбент } & \multirow{2}{*}{\multicolumn{2}{|c|}{$\begin{array}{c}\text { Сорбция } \\
\text { ГА-титр (ГАЕ) }\end{array}$}} & \multicolumn{4}{|c|}{ Десорбция после УЗ-обработки } \\
\hline & & & & \multirow{3}{*}{$\begin{array}{c}\text { Время УЗ- } \\
\text { обработки } \\
\text { комплекса } \\
\text { «+С»* } \\
\text { мин }\end{array}$} & \multirow{2}{*}{\multicolumn{2}{|c|}{$\begin{array}{c}\text { Титр вируса в надосад- } \\
\text { ке- } 2\end{array}$}} & \multirow{3}{*}{$\begin{array}{c}\text { Инфекционный } \\
\text { титр комплекса } \\
\text { «В+С»**, } \\
\operatorname{lgТЦИД~}\end{array}$} \\
\hline & & \multirow{2}{*}{$\begin{array}{c}\text { Вируса* } \\
\text { до сорб- } \\
\text { ции }\end{array}$} & \multirow{2}{*}{$\begin{array}{c}\text { в «надосад- } \\
\text { ке-1» после } \\
\text { сорбции }\end{array}$} & & & & \\
\hline & & & & & $\begin{array}{c}\text { ГА- } \\
\text { титр } \\
\text { (ГАЕ) }\end{array}$ & 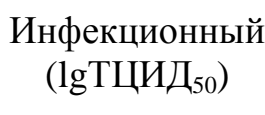 & \\
\hline 1 & \multirow{4}{*}{ PPy } & \multirow{4}{*}{512} & 2 & 0 & 2 & 0 & 0 \\
\hline 2 & & & 16 & 5 & 4 & 0 & 0 \\
\hline 3 & & & 16 & 15 & 8 & 0 & 0 \\
\hline 4 & & & 16 & 30 & 2 & 0 & 0 \\
\hline
\end{tabular}

Примечание: комплекс «В+C»* - комплекс «вирус+сорбент».

Возможность выделения вируса только в разрушенном состоянии свидетельствуют о его эффективном связывании полимером. В совокупности с отсутствием инфекционной активности и осадка, и жидкой фазы эти результаты, говорят о безопасности отработанного сорбента с точки зрения заражения. В тоже время применение УЗ открывает перспективы регенерации сорбента для многократного его использования.

\section{Заключение}

Исследована эффективность связывания вирусов гриппа электропроводящим полимером полипирролом. РРу сорбирует вирус из водной среды, снижая его концентрацию от 32 до 256 раз. Показано, что комплекс «сорбент+вирус» не выделяет вирус при диспергировании в свежей порции физиологического раствора. Независимо от температурной и ультразвуковой обработки ни в водной фазе, ни в комплексе «сорбент+вирус» не обнаруженная инфекционная активность. Однако низкочастотный ультразвук малой мощности десорбирует вирус с полимера, что сопровождается разрушением вируса и деструкцией его наружной оболочки. Термообработка самого РРу показала, что при прогреве вплоть до $100^{\circ} \mathrm{C}$ его сорбционная активность в отношении вирусов не снижается. Таким образом, взаимодействие РРу с вирусом следует отнести скорее к категории хемосорбции, нежели слабых физических Ван-дерВаальсовых взаимодействий. Полимер прочно удерживает сорбированный вирус, подавляя его инфекционность. Однако результаты по десорбции «мертвого» вируса ультразвуком открывают перспективы регенерации сорбента и многократного его использования.

\section{Список литературы}

1. Климов Е. С., Бузаева М. В. Природные сорбенты и комплексоны в очистке сточных вод // Под общей редакцией Е. С. Климова. Ульяновск: УлГТУ. 2011.201 С.

2. Черенкова Ю.А., Котова Д.Л., Крысанова Т.А., Гречкина М.В. и др. // Сорбцион- ные и хроматографические прочессы. 2007. T. 7. № 5. C. 867-877.

3. Котова Д.Л., Крысанова Т.А., Селеменев В.Ф. // Журн. физич. химии. 1999. Т. 73. № 7. С. 1316-1318.

4. Сыромятников М.Ю., Лопатин А.В., Кокина А.В. и др. // Сорбционные и хрома- 
тографические прочессы. 2016. Т.16. № 2. С. 251-257.

5. Handbook of Conducting Polymers. Conjugated Polymers: Theory, Synthesis, Properties and Characterization. 3d ed. / Eds. T.A. Skotheim, J.R. Reynolds // Boca Raton, CRC Press. 2007, pp. 260-346.

6. Stejskal J., Trchová M., Bober P., Humpolíček P. et al. // In: Encyclopedia of Polymer Science and Technology. John Wiley \& Sons. 2015 , pp. 1-44. DOI: 10.1002/0471440264.pst640

7. Shandry V., Kim K.S. // Chemical Communications. 2011. Vol. 47, pp. 3242-3944.

8. Mansour M.S., Ossman M.E., Farag H.E. Mansour M.S. // Desalination. 2011. Vol. 272, pp. 301-305.

9. Bhaumik M., Maity A., Srinivasu V.V., Onyango M.S. // J. Hazard. Mater. 2011. Vol. 190. No 1-3, pp. 381-390.

10. Оксанич А.С., Марова А.А., Файзулоев Е.Б., Кривцов Г.Г. и др. Патент РФ №2444011. 2012. Бюллетень № 6.

11. Иванова В.Т. Гарина Е.О., Николаева Т.Н., Суетина И.А. и др. // Вода: химия и экология. 2016. № 10. С. 71-81.

12. Сапурина И.Ю., Иванова М.В., Иванова В.Т., Бурцева Е.И. и др // Высокомолекулярные соединения. Серия А. 2014. Т. 56. № 4. С. 389-398.

\section{References}

1. Klimov E. S., Buzaeva M. V. Prirodnye sorbenty i kompleksony $\mathrm{v}$ ochistke stochnyh vod , Pod obshhej redakciej E. S. Klimova, Ul'janovsk: UlGTU, 2011, $201 \mathrm{p}$.

2. Cherenkova Ju.A., Kotova D.L., Krysanova T.A., Grachkina M.V. et al., Sorbtsionnye $i$ khromatograficheskie protsessy, 2007, Vol. 7, No 5, pp. 867-877.

3. Kotova D.L., Krysanova T.A., Selemenev V.F. , Zhurn. fizich. himii. 1999. Vol. 73, No 7, pp. 1316-1318.

4. Syromjatnikov M.Ju., Lopatin A.V., Kokina A.V., Sal'nikov A.V. et al., Sorbtsionnye $i$ khromatograficheskie protsessy, 2016, Vol. 16, No 2, pp. 251-257.

5. Handbook of Conducting Polymers. Conjugated Polymers: Theory, Synthesis, Properties and Characterization. 3d ed. / Eds. T.A. Skotheim, J.R. Reynolds, Boca Raton, CRC Press. 2007, pp. 260-346.
13. Гарина Е.О., Иванова В.Т., Носик Н.Н., Кондрашина Н.Г. и др. // Нанотехнологии: разработка, применение - XXI век. 2016. Т. 8. № 2. C. 3-13.

14. Ivanova V.T., Garina E.O., Burtseva E. I., Kirillova E.S. et al. // Chemical Papers. 2017. Vol. 71. No 2. pp. 495-503. DOI 10.1007/s11696-016-0068-5.

15. Иванова В.Т., Иванова М.В, Носик Н.Н., Бурцева Е.И.и др. // Биотехнология. 2014. № 3 .C. 67-72.

16. Huang W.-S., Humphrey B.D., MacDiarmid A.G. // J. Chem. Soc. Faraday Trans. 1 Phys. Chem. Condens. Phases. 1986. Vol. 82. No 8. pp. 2385-2400.

17. Stejskal J., Prokeš J., Sapurina I. // Materials Letters. 2009. Vol. 63. No 8. pp. 709-711.

18. Иванова В.Т., Иванов В.Ф., Курочкина, Я.Е., Грибкова О.Л. и др. // Bопросы вирусологии. 2009. № 3. С. 21- 26.

19. Pandey S.S., Gerard M., Sharma A.L., Malthora B.D. // J. Appl. Polym. Sci. 2000. Vol. 5. pp. 149[155.

20. Антушева Т.И. Некоторые особенности влияния ультразвука на микроорганизмы // Живые и биокосные системы. 2013. № 4. Режим доступа: http://www.jbks.ru/archive/issue-4/article-11 (дата обращения: 03.05.2017).

6. Stejskal J., Trchová M., Bober P., Humpolíček P. et al., In: Encyclopedia of Polymer Science and Technology. John Wiley \& Sons. 2015, pp. 1-44. DOI: 10.1002/0471440264.pst640

7. Shandry V., Kim K.S., Chemical Communications, 2011, Vol. 47, pp. 3242-3944.

8. Mansour M.S., Ossman M.E., Farag H.E. Mansour M.S., Desalination, 2011, Vol. 272, pp. 301-305.

9. Bhaumik M., Maity A., Srinivasu V.V., Onyango M.S., J. Hazard. Mater, 2011, Vol. 190, No 1-3, pp. 381-390.

10.Oksanich A.S., Marova A.A., Fajzuloev E.B., Krivcov G.G. ey al., Patent RF No 2444011. 2012. Bjulleten' No 6.

11.Ivanova V.T. Garina E.O., Nikolaeva T.N., Suetina I.A. et al., Voda: himija i jekologija. 2016, No 10, pp. 71-81.

12.Sapurina I.Ju., Ivanova M.V., Ivanova V.T., Burceva E.I. et al., Vysokomolekuljarnye 
soedinenija. Serija A, 2014, Vol. 56, No 4, pp. 389-398.

13.Garina E.O., Ivanova V.T., Nosik N.N., Kondrashina N.G.ey al., Nanotehnologii: razrabotka, primenenie - XXI vek. 2016, Vol. 8, No 2, pp. 3-13.

14.Ivanova V.T., Garina E.O., Burtseva E. I., Kirillova E.S. et al. Chemical Papers. 2017. Vol. 71, No 2, rr. 495-503. DOI 10.1007/s11696-016-0068-5.

15.Ivanova V.T., Ivanova M.V, Nosik N.N., Burceva E.I., Kondrashina N.G. i dr. , Biotehnologija. 2014, No 3, pp. 67-72.

16.Huang W.-S., Humphrey B.D., MacDiarmid A.G. , J. Chem. Soc. Faraday Trans. 1

Иванова Валерия Тимофеевна - д.б.н., ведущий научный сотрудник, лаб. этиологии и эпидемиологии гриппа ФГБУ Институт вирусологии им. Д.И. Ивановского «ФНИЦЭМ им. Н.Ф. Гамалеи» Минздрава России, Москва.

Гарина Екатерина Олеговна - научный сотрудник, лаб. этиологии и эпидемиологии гриппа ФГБУ Институт вирусологии им. Д.И. Ивановского «ФНИЦЭМ им. Н.Ф. Гамалеи» Минздрава России, Москва

Сапурина Ирина Юрьевна - д.Х.н., ведущий научный сотрудник, лаб. анизотропных и структурированных полимерных систем, Институт высокомолекулярных соединений РАН, Санкт-Петербург.

Стейскал Ярослав - к.х.н, зав. лаб. проводящих полимеров, Институт макромолекулярной химии Академии наук Чешской Республики, Прага.

Грибкова Оксана Леонидовна - к.Х.н. старший научный сотрудник лаб. электронных и фотонных процессов в полимерных наноматериалах» ФГБУН Институт физической химии и электрохимии им. А. Н. Фрумкина РАН, Москва

Кириллова Елена Сергеевна, к.б.н. ведущий научный сотрудник лаб. этиологии и эпидемиологии гриппа ФГБУ Институт вирусологии им. Д.И. Ивановского «ФНИЦЭМ им. Н.Ф. Гамалеи» Минздрава России, Москва

Иванов Виктор Федорович - д.х.н., ведущий научный сотрудник лаб. электронных и фотонных процессов в полимерных наноматериалах» ФГБУН Институт физической химии и электрохимии им. А. Н. Фрумкина РАН, Москва

Бурцева Елена Ивановна - Д.м.н., зав. лаб. этиологии и эпидемиологии гриппа ФГБУ Институт вирусологии им. Д.И. Ивановского «ФНИЦЭМ им. Н.Ф. Гамалеи» Минздрава России, \Москва
Phys. Chem. Condens. Phases, 1986, Vol. 82, No 8, pp. 2385-2400.

17.Stejskal J., Prokeš J., Sapurina I., Materials Letters. 2009. Vol. 63, No 8, pp. 709-711.

18.Ivanova V.T., Ivanov V.F., Kurochkina, Ja.E., Gribkova O.L. et al., Voprosy virusologii, 2009, No 3, pp. 21-26.

19.Pandey S.S., Gerard M., Sharma A.L., Malthora B.D. , J. Appl. Polym, Sci, 2000, Vol. 5, pp. 149-155.

20.Antusheva T.I. Nekotorye osobennosti vlijanija ul'trazvuka na mikroorganizmy, Zhivye $i$ biokosnye sistemy. 2013. № 4. Rezhim dostupa: http:,www.jbks.ru/archive/issue-4/article-11 (data obrashhenija: 03.05.2017).

Ivanova Valeria T. - Dr.Sci.(virology) Leading researcher, Lab of etiology and epidemiology of influenza D.I. Ivanovsky Institute of Virology FSBI "N.F. Gamaleya FRCEM" MoPH of the Russian Federation, e-mail: valivanova1946@mail.ru

Garina Ekaterina O. - researcher, Lab of etiology and epidemiology of influenza D.I. Ivanovsky Institute of Virology FSBI "N.F. Gamaleya FRCEM" MoPH of the Russian Federation, e-mail: kattymos@mail.ru

Sapurina Irina Yurevna Dr.Sci. (Chem), Leading researcher, Lab Laboratory of anisotropic and structureted polymer sistems, Institute of Macromolecular Compounds, Russian Academy of Sciences, Saint-Petersburg, Russian Federation, e-mail: sapurina@mail.ru

Stejskal Jaroslav PhD. Head of the Lab of conductive polymers, Institute of Macromolecular Chemistry, Academy of Sciences of the Czech Republic, Prague, Czech Republic, e-mail: stejskal@imc.cas.cz Gribkova Oxana Leonidovna - $\mathrm{PhD}$, senior researcher, lab. "Electronic and photonic processes in polymeric nanomaterials" A.N. Frumkin Institute of Physical Chemistry and Electrochemistry RAS, Moscow, Russia, e-mail: oxgribkova@gmail.com

Kirillova Elena Sergeevna - $\mathrm{PhD}$, leading researcher, lab of etiology and epidemiology of influenza D.I. Ivanovsky, Institute of Virology FSBI "N.F. Gamaleya FRCEM" MoPH of the Russian Federation, e-mail: esshevchenko@yandex.ru

Ivanov Victor Fedorovich - Dr. Sci.(Phis/Chem) Leading researcher, Lab "Electronic and photonic processes in polymeric nanomaterials", A.N Frumkin Institute of Physical Chemistry and Electrochemistry RAS, Moscow, Russia, e-mail: vikigolovin@yandex.ru

Burtseva Elena Ivanovna Dr.Med.Sci, Head of the Lab. of etiology and epidemiology of influenza D.I. Ivanovsky Institute of Virology FSBI "N.F. Gamaleya FRCEM" MoPH of the Russian Federation, e-mail: elena-burtseva@yandex.ru 